\title{
A trama do crédito: entre o café e o consumo conspícuo em uma loja de Ribeirão Preto - 1891 e $1892^{1}$
}

The credit plot: between coffee and conspicuous consumption in a shop in ribeirão preto - 1891 and 1892

Carlo Guimarães Monti*

Universidade Federal do Sul e Sudeste do Pará (UNIFESSPA), Marabá, PA, Brasil

RESUMO: Neste artigo estudamos a loja que o Coronel Joaquim da Cunha Diniz Junqueira teve em Ribeirão Preto, um estabelecimento comercial que vendia produtos industrializados e produzidos localmente. Isso nos possibilitou verificar o curso do comércio em várias esferas, em um trabalho que teve como base a análise do livro-caixa da loja, existente no Arquivo Pessoal - Documentação da Fazenda Boa Vista (APFBV), para os anos de 1891 e 1892; também desvendar a forma de relação econômica que se dava entre a loja, os clientes e os fornecedores; e, ainda, identificar a função desse comércio na cadeia de negócios de seu proprietário. Verificamos a importância da comercialização do café, que servia de moeda para muitas das combinações realizadas na trama do crédito. O café foi a alavanca para a concessão de crédito, de tal modo que a loja não fornecia somente produtos industrializados ou agrícolas, mas, também, crédito.

PALAVRAS-CHAVE: Consumo. Crédito. Ribeirão Preto.

\begin{abstract}
In this article, the object of study was the store owned by Coronel Joaquim da Cunha Diniz Junqueira in Ribeirão Preto, which sold manufactured goods and also local products. That made it possible to verify the trading flow in several spheres. The Study was based on the analysis of the cash book found in private files in the Boa Vista Farm Documentation, during the years 1891 and 1892, which allowed to clarify how the commercial relationship was given among the store, customers and suppliers and with that, we could identify the role of that commerce in the chain business of its owner. We could also check the importance of the coffee trading, which was used as currency for many of the credit relationships. Coffee was the financial leverage for granting credit, in such way that, the store did not only supply manufactured goods or agricultural products, but also credit.
\end{abstract}

KEYWORDS: Consumption. Credit. Ribeirão Preto.

\footnotetext{
* Professor adjunto na Universidade Federal do Sul e Sudeste do Pará (UNIFESSPA), Marabá, PA, Brasil. Doutor em história pela Universidade Estadual Paulista Julio de Mesquita Filho (UNESP). E-mail: carlogmonti@gmail.com https://orcid.org/0000-0002-7980-5906.
} 


\section{Introdução}

Ribeirão Preto está localizado na região nordeste do estado de São Paulo e foi desmembrado de São Simão em 1871 com o nome de "Villa da Capela de São Sebastião do Ribeirão Preto", época em que tinha uma população composta por brasileiros brancos, solteiros, católicos, analfabetos e negros, dos quais eram 857 escravos, em um total de 5.552 habitantes (LOPES, 2015). A cafeicultura teve um rápido desenvolvimento na cidade com as primeiras plantaçôes registradas em 1872, na região; em 1868, já temos notícias de cafezais.

A cafeicultura, os imigrantes e a chegada da ferrovia, em 1883, contribuíram para um rápido crescimento: em 1886, eram 10.420 habitantes e, em 1900, já eram 59.195. Em quatorze anos, a população cresceu 568,09\%. Nessa época, os negócios urbanos deveriam ser de grande rentabilidade: "[...] em 1890 o município possuía 186 estabelecimentos comerciais. Desses, 38,70\% eram armazéns de secos e molhados, e 14,51\% eram açougues; outros $14,51 \%$ vendiam tecidos, armarinhos [...]” (OLIVEIRA, 2006, p. 45).

Entre 1890-1914, a cidade passou por um crescimento de 69,70\% no total dos estabelecimentos. "Foram localizados, durante o período 1890-1914, 24 estabelecimentos financeiros, a saber: 4 bancos e 2 capitalistas em 1890; 3 bancos, 1 casa de câmbio e 1 capitalista em 1904; e 5 bancos e 8 capitalistas em 1914” (LOPES, 2015, p. 309).

Tendo em vista o crescimento populacional e econômico pelo qual a cidade passou, este artigo justifica-se como uma possibilidade de compreendermos a dinâmica de consumo e os elementos estimuladores que sustentavam uma rede de crédito, em uma época marcada por reformas monetárias conturbadas, como foi o caso do encilhamento.

Buscamos, neste artigo, trabalhar a história de uma loja em Ribeirão Preto, entre os anos de 1891 e 1892, que atuava em vários seguimentos, desde produtos já consagrados até novos produtos de luxo trazidos através da ferrovia. Esse comércio pertencia a Joaquim da Cunha Diniz Junqueira, membro de uma família tradicional, que chegou a ser um dos maiores cafeicultores da cidade e líder do PRP (Partido Republicano Paulista) local, durante trinta anos, o que lhe rendeu o título de coronel dos coronéis.

Por meio da análise de uma documentação inédita e pouco trabalhada na literatura, temos como objetivo inicial comprovar como o café estimulou o consumo ao ser utilizado como meio de pagamento de parte das compras realizadas na loja. Também procuramos demonstrar como o café estimulou o crédito ao garantir os gastos realizados na loja. Em última instância, estamos estudando as várias facetas de um estabelecimento comercial, em época do encilhamento, que usava o café como meio pagante e que passou a ter feiçôes de banco.

Os dados ora analisados são do livro de número 2 da loja de Joaquim da Cunha, um documento que registra o período entre junho de 1891 e abril de 1892 e trata de contas que estavam em movimento, algumas sendo abertas, outras fechadas. Esse tipo de documento é pouco estudado devido à sua escassez e à dificuldade de acesso e, em especial, por ser composto somente por números e nomes, não há nessa fonte uma textualidade que conecte as informações contábeis.

O livro de contabilidade tinha por função fazer o registro diário de todo movimento de compra e venda, por meio de entrada dos nomes dos compradores e fornecedores que ali realizavam negócios. À frente dos nomes, em haver e dever, era registrado o movimento diário da loja; também era registrada a conta corrente junto ao Banco Ribeirão Preto. 
Através desse livro de 1891, o mais antigo que encontramos no Arquivo Pessoal - Documentação da Fazenda Boa Vista -, pudemos notar uma das preocupaçóes constantes nos negócios realizados por Joaquim: o uso da contabilidade como forma de controle das contas. A personificação das contas e o controle entre devedores e credores demonstram que a contabilidade era percebida como uma forma de se tomarem decisóes econômicas, analisando entre seus clientes e fornecedores aqueles que eram oportunos de receberam crédito.

A historiografia tem verificado a importância do crédito para a cafeicultura em Ribeirão Preto e regióes próximas (TOSI; FALEIROS; FONTANARI, 2011; FONTANARI, 2015; OLIVEIRA; MARCONDES, 2018; MARCONDES, 2018). O café movimentou diversos recursos e vários desenhos de financiamento, pois "Grandes negociantes, capitalistas, comissários, bancos e casas bancárias e exportadoras assumiram papel relevante no financiamento dos cafeicultores" (OLIVEIRA; MARCONDES, 2018, p. 229).

Certamente que a cafeicultura utilizou uma variada forma de levantar recursos, em especial, para a fase inicial na formação dos grandes cafezais que é justamente o período coberto pela nossa documentação, possibilitando avançarmos nas discussões que tem como foco a constituição e a origem da riqueza que permitiu a alguns cafeicultores chegarem à condição de se colocarem entre os grandes produtores de café e, assim, passar a contar com o financiamento hipotecário (MARCONDES, 2018).

No período de formação desses patrimônios, vemos uma aliança de atividades sendo promovida por Joaquim da Cunha, em um tripé marcado pelo comércio, pelo crédito e pela política, esses que serão os elementos iniciais de sua acumulação, sendo que alguns trabalhos apontam esse caminho para outras regiões que não Ribeirão Preto (ANDRADE, 2008; FONTANARI, 2015). De tal modo, buscamos estudar uma fase das atividades econômicas desenvolvidas por Joaquim em um momento em que estava promovendo uma diversificação de suas atividades; a loja era uma dessas frentes, a política e o crédito eram outras. Em 1890, Joaquim da Cunha tinha sido eleito para o Conselho de Intendência, mas teve o seu mandato cassado em 1892, o que lhe deve ter causado uma grande frustração, pois a família Junqueira estava presente na Câmara desde o início de seu funcionamento, em 1874(GODOY, 2006). O retorno à vida pública ocorreu somente em 1902, já como líder do PRP local, cargo que preservou até a morte, em 1932. Acreditamos que o retorno à política teve uma relação íntima com a sua ascensão no campo econômico, que foi estimulada pelos negócios oriundos da loja. Considerado por muitos como o "Coronel dos Coronéis”, em Ribeirão Preto, controlou a política local e regional durante anos, a ponto de eleger dois presidentes da Província e um Presidente da República: Washington Luís. No campo econômico, foi proprietário da Fazenda Boa Vista, em Ribeirão Preto, que no início do século XX passou a ter 650.000 pés de café, plantados em uma área de 2.160 alqueires. Em 1916, somente dez produtores possuíam mais de 501 mil pés de café na cidade; nesse ano, a Fazenda Boa Vista passou a ser indicada como a quinta maior produtora de café no município e permaneceu entre a quinta e a sexta posição, até 1923 (ARQUIVO PÚBLICO E HISTÓRICO DE RIBEIR ÃO PRETO. Imposto de cafeeiros, anos de 1916 a 1930). 


\section{Fornecedores, produtos industrializados versus café}

O período registrado no documento aborda 219 contas, um número que nos permitiu acompanhar o cotidiano da loja. Do conjunto das contas, 175 eram de clientes, desses 25 eram de empresas que compravam na loja e 44 eram de empresas fornecedoras de produtos; e são esses números, assim especificados, que denotam o leque variado de produtos que eram disponibilizados à venda. Os produtos mais vendidos eram fósforos, velas, querosene, cerveja, açúcar, sal, alho, batata, banha, chinelos, dentre outros. Além de produtos de uso cotidiano, a loja trabalhava com produtos de luxo, roupas e alimentos. Para compreendermos a extensão e o significado dos negócios que a loja realizava, inicialmente vamos analisar os seus fornecedores e, depois, os consumidores.

Entre os 44 fornecedores, estava Zerrener, Bullow E Cia., que era representante consular da Bélgica, agente de uma firma de navegação alemã e empresa importadora e exportadora, além de ter a sua história econômica ligada à Antarctica. As cervejas eram um dos principais produtos adquiridos pelos clientes da loja, e entre elas uma marca se destaca, a Cerveja Spaten (A Cervejaria mais antiga de Munique). Seu valor de venda variou entre $1 \$ 205$ e 1\$500, em novembro de 1891, tendo chegado a $1 \$ 800$, em março de 1892 . A cada semestre ou quadrimestre, os preços dos produtos vendidos na loja eram alterados.

Segundo os registros, Procópio José Alves (APFBV. Livro, n. 2, 06/1891 a 04/1892) era um comprador de cerveja Spaten e de outras bebidas alcoólicas. Em seis meses de conta, comprou bebidas, no máximo duas garrafas por vez. Quando encontramos a conta dele, devia 330\$240; desse valor, havia pago $284 \$ 000$. Depois disso, consumiu diversos produtos durante seis meses, quando, então, fez um novo pagamento de $200 \$ 000$, que não liquidou a sua conta. Procópio Alves, além de fazer os seus pagamentos a cada seis meses, em seis de junho, pagou por duas garrafas de Spaten o valor de $3 \$ 000$, enquanto o valor cobrado de outros clientes, nessa época, para uma garrafa, era de $1 \$ 205$, uma diferença de $23 \%$. Notamos que a loja podia trabalhar com mais de uma tabela de preços, que variava conforme o empenho do pagante em saldar as suas contas.

A loja trabalhava com um conjunto de produtos industrializados que eram vendidos, como o Papel Diplomata, que teve seu valor reajustado de $1 \$ 800$, em janeiro de 1891 , para $2 \$ 500$; a garrafa de Água Seltz, que foi de $0 \$ 700$, em julho, para $0 \$ 800$, e, em abril de 1892 , foi para $1 \$ 000$; o Conbaque Brizard, que variou de 4\$500, em abril, para 6\$500; as Velas Clichy, de 1\$200, em novembro, para $1 \$ 500$, e, em março, de 1892 , foi para $1 \$ 800$; o Sabonete Rimel, com valor de 1\$500, e o Arroz Carolina. Seus valores sofreram constantes variações que, em média, chegaram a $44 \%$, o que poderia ser uma compensação pela inflação do período, marcado pelo encilhamento entre 1888 e 1892 que foi especulativo e inflacionista.

$\mathrm{Na}$ época em que Rui Barbosa, então ministro da Fazenda, argumentava que o Brasil era um país de propensão ao entesouramento, seria necessário, para fazer circular moeda, uma maior quantidade de emissóes primárias. Essa visão justificava a expansão monetária pela necessidade de negócios, acarretando em emissóes monetárias que culminaram em um período de fortes variaçóes das taxas de câmbio e dos preços. "O fracasso desse sistema, entretanto, parecia dever-se ao avanço da especulação bursátil, que resultou em oferecer oportunidade de aplicações financeiras mais atraentes que as letras hipotecárias” (FRANCO, 1987, p. 101).

As reformas econômicas do período possibilitaram em 1880 a atuação dos bancos universais com atuação em várias funções de crédito, em muitas atividades comerciais, como “[...] empréstimos 
de curto prazo, descontos e câmbio; as atividades de crédito agrícola e a hipotecária, como a provisão de financiamentos de longo prazo, garantidos por propriedades imobiliárias rurais ou urbanas, e adiantamentos contra colheitas futuras [...]” (MARCONDES; HANLEY, 2010, p. 112). Essa expansão do crédito bancário facilitou o aparecimento de sociedades anônimas que representam boa parte das empresas que encontramos na análise do livro caixa da loja.

No ano de 1891, ter marcas para produtos como água, velas, sabonetes e papel era, no mínimo, o indício de um tipo de consumo muito específico que estava em ascensão. A ferrovia, que chegou a Ribeirão Preto em 1883 (LOPES, 2015), promoveu o elo com o comércio de São Paulo e com o porto de Santos, trazendo os novos tempos do progresso e, com ele, a modernidade (CAMPOS, 2002). Uma comparação entre os anos de 1874 e 1910 mostra um aumento, durante esse período, de $504,3 \%$ no número de viagens, e de $991,8 \%$ na tonelagem de toda a navegação nacional e estrangeira, a vapor e a vela. (LLOYD, 1913).

O variado grupo de fornecedores somaram $20 \%$ das contas registradas no livro. As compras da loja junto aos fornecedores aconteciam entre julho e setembro, junto aos fornecedores é outro indício de que o café estava atrelado ao movimento comercial de Ribeirão, à época, pois eram os meses em que o café começava a ser colhido, momento em que a circulação de dinheiro daria vazão às novidades disponibilizadas na loja. Os pagamentos eram feitos aos fornecedores entre dezembro e fevereiro do ano seguinte, com faturas a serem pagas num prazo de três e seis meses.

Quando a loja não pagava o valor total da fatura, recebia a visita do representante ou sócio das empresas que eram Companhias. Os pagamentos eram feitos via depósito em banco, envio de cheque ou pagamento ao representante ou ao sócio da firma. Das 44 firmas, 23 tinham representantes que visitavam a loja, e o Banco de Ribeirão Preto era o banco utilizado como intermediário nos pagamentos das faturas.

Os fornecedores de produtos podem ser divididos em dois grupos. Quanto aos valores que eram vendidos, dezenove deles, ou seja, $43 \%$ fizeram vendas de valores que não passaram de um mil réis e que somaram $8 \%$ das vendas feitas para a loja. O outro grupo de 25 fornecedores foi responsável por $92 \%$ das vendas feitas para a loja, ver gráfico 1 . Os fornecedores que venderam até 1.000 réis o fizeram para esses valores serem pagos no período de três a quatro meses; em média, as vendas desse grupo ficaram em 513\$000; ao todo, venderam 9:745\$000 para a loja.

Dentre esses fornecedores, estava a Abrate Irmão e Baroni que, desde o final do século XIX, estabeleceu uma casa de joias na rua XV de Novembro, n. 43, em São Paulo (BARBUY, 2006). A loja de Joaquim da Cunha comprou desse fornecedor $568 \$ 000$ em joias (APFBV. LIVRO, n. 2, p. 237). Outro fornecedor foi a Companhia Impressoura Paulista, que controlou o jornal A Provincia de S. Paulo, o atual O Estado de São Paulo. Vendeu $164 \$ 800$ em jornais à loja, em 6 meses (APFBV. LIVRO, n. 2, p. 236), época em que o jornal estava afinado com o PRP e tinha, entre seus acionistas, Américo Brasiliense e Manuel Ferraz de Campos Salles. Com a ferrovia, os jornais e suas novas ideias também chegavam em Ribeirão Preto, em uma época em que a população estava crescendo rapidamente. 
Gráfico 1 - Número de companhias e vendas em porcentagem nos anos de 1891 e 1892

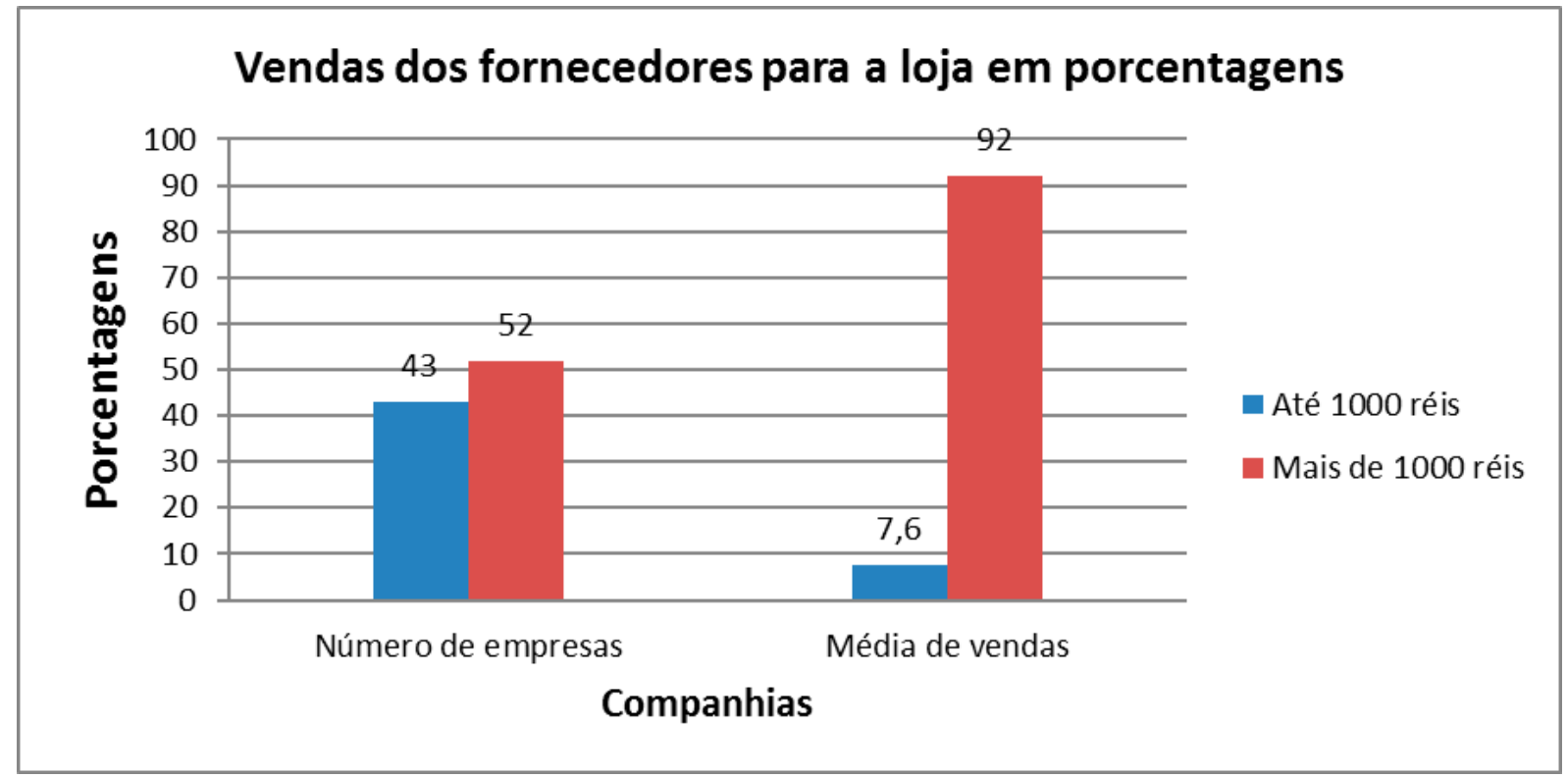

Fonte: Arquivo Pessoal Fazenda Boa Vista - APFBV. Livro, n. 2, 06/1891 a 04/1892.

Joaquim da Cunha, desde o seu casamento, em 1879, já residia na cidade. Por ser um morador antigo, enraizado e atento aos movimentos econômicos, certamente conseguiu perceber e antever a dinâmica pela qual a cidade estava passando. Além disso, colocava-o em situação favorável à realização dos negócios o seu elo com São Paulo, que se dava por meio da ferrovia, e suas sucessivas hospedagens no Hotel França, um hotel do século XIX, localizado no Largo do São Bento, bem ao lado das lojas Abrate Irmão e Baroni e a Piçarra Liberal, que eram fornecedoras de sua loja.

As viagens a São Paulo, o contato com o triângulo do consumo, "[...] o Triângulo Comercial, formado pelas ruas São Bento, Direita e XV de Novembro [...]” (OLIVEIRA, 2014, p. 95) o acesso às discussões políticas veiculadas pelo jornal $A$ Provincia de $S$. Paulo e um antigo conhecimento de Ribeirão e região, originário de seus antepassados, a família Junqueira. Tais contatos permitiram a Joaquim estabelecer um conjunto de fornecedores e produtos a serem comercializados que contou com uma clientela que depositou nele a sua confiança. Tudo isso foi organizado e observado por meio de uma contabilidade pormenorizada.

Além do grupo de fornecedores que venderam até mil réis, temos o outro grupo de 25 empresas que venderam acima de 1:000\$000. Esse grupo vendeu, em média, 5.195\$560. Somando todas as vendas dessas firmas, chegamos a 142:712\$000, números que, somados ao valor total da loja, com vendas menores de mil réis, atingem um total de 152:457\$000. Esse foi o movimento de compra da loja de Joaquim da Cunha para um período de um ano, ver Gráfico 2. 
Gráfico 2 - Movimento de compra e venda da loja

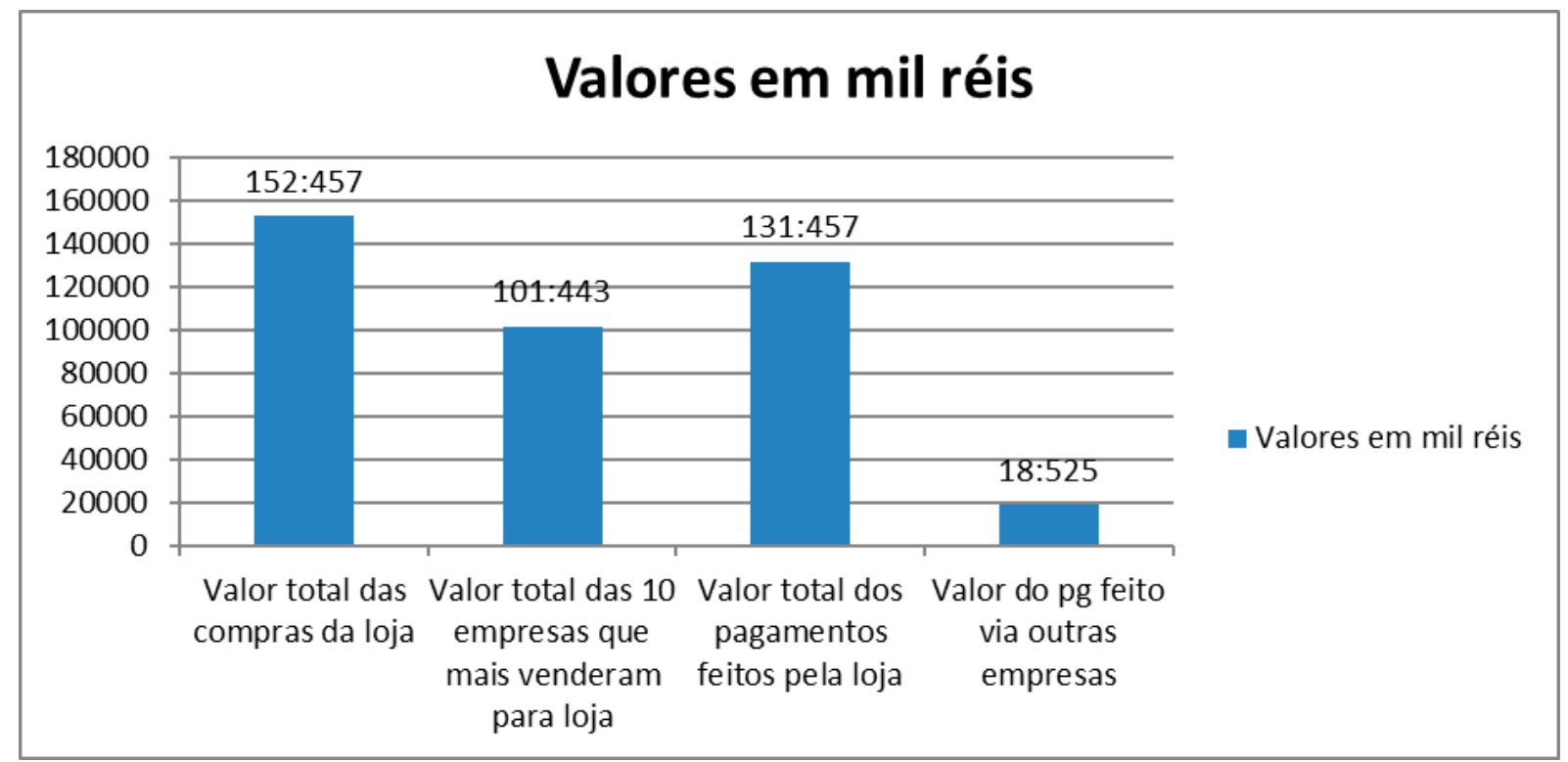

Fonte: APFBV. Livro Loja, n. 2, 06/1891 a 04/1892.

Uma das empresas que tiveram maior diferença entre o que foi vendido e o que ficou por pagar foi a C. Costa e Cia (APFBV. Livro, n. 2. p. 225), que vendeu durante todo o período para a loja um total de 8:170\$000, e recebeu de pagamento 5:175\$760. Duas das faturas pagas a essa empresa foram geradas por meio de outra firma, a Coimbra Irmão e Curvelo, e ainda ocorreram transaçóes em que uma terceira firma entrou no negócio, indicando uma rede de comércio alargada.

A loja comprou da C. Costa e Cia, pagou parte do valor enviando café a essa empresa, negociação que somou 2:471\$970; além disso, outra parte do valor foi pago pela Coimbra Irmão e Curvelo (APFBV. Livro, n. 2, p. 306), que repassou 1:029\$760 diretamente à C. Costa e Cia, e os outros 1:442\$210 pagou a uma terceira empresa, a Silva Barbosa e Cia, embora tais valores tenham sido abatidos da dívida que a loja tinha com a C. Costa e Cia.

Então, a loja recebeu produtos industrializados, pagou parte em café, pagou parte por meio de outros fornecedores, abatendo tudo da dívida com a C. Costa e Cia. O mais interessante é que tanto os pagamentos feitos pela Coimbra Irmão e Curvelo, assim como o café enviado pela loja à $C$. Costa e Cia somam o mesmo valor: 2:471\$970. A loja pagou a sua dívida em dois momentos: um, com café, outro, por meio dos pagamentos feitos pela Coimbra Irmão e Curvelo.

Quando acompanhamos a conta das outras empresas, vemos que: a C. Costa e Cia (APFBV. Livro, n. 2, p. 225), em 07 de setembro de 1891, teve registrada “[...] uma ordem que lhe remetemos contra a Coimbra Irmão e Curvelo 1:629\$76”. Assim como quando acompanhamos as contas da Silva Barbosa e Cia (Livro, n. 2, 06/1891 a 04/1892. p. 235) e encontramos em 24 de setembro “[...] uma ordem que lhe remetemos contra a Coimbra Irmão e Curvelo 1:442\$210". Somados os valores, temos um total de 3:071\$970, quantia que foi descontada dessas empresas.

Contudo, o valor sacado da $C$. Costa e Cia foi de 2:471\$970, e o valor descontado das empresas foi de 3:071\$970, uma diferença de 600\$000, o que dá 19\% de lucro sobre a transação total, que ficou com a loja de Joaquim da Cunha, um lucro que foi conseguido pela intermediação entre companhias e ainda tendo como meio circulante o café. 
Não só com a venda de produtos industrializados negociava a loja, mas, também, com a atividade comercial entre companhias, que passava pela transação do café e outros gêneros agrícolas, como foi o caso da Silva Barbosa e Cia: em sete de agosto, a loja envia cinquenta alqueires de feijão à companhia, que em quatro de setembro paga por ele $297 \$ 000$.

O valor do feijão enviado serviu para pagar uma das maiores transaçóes que a loja fez com uma empresa, para a qual devia 16:018\$700, tendo pago 10:654\$060 a Silva Barbosa e Cia. A dívida foi contraída em 21 transaçôes, que geravam faturas a serem pagas entre dois e quatro meses. Já os pagamentos, foram feitos por meio de dez transações, e o interessante é que, em seis delas, o pagamento foi feito por outras empresas e/ou pessoas. As faturas foram pagas pelo envio de feijão, por ordem de pagamento via Penteado e Dumont, Cordeiro e Mello, Coimbra e Irmãos, João Guimarães e Cia e ao Sr. Francisco Albermaz. Tais valores somaram 6:144\$000 dos 10:654\$060 pagos à empresa Silva Barbosa e Cia, que fornecia à loja vários produtos, e que, na hora de receber, teve os pagamentos feitos por outras empresas, ou seja, 57\% do valor pago a Silva Barbosa e Cia foi realizado por meio de outras empresas.

Suscita-se, portanto, a questão: o valor descontado das outras empresas foi igual àquele pago a Silva Barbosa e Cia? Joaquim da Cunha estava intermediando um circuito econômico entre vários fornecedores e a Silva Barbosa e Cia, que poderia ser feito por meio de notas promissórias e ou empréstimos, e tal circuito se concretizava nos meses da colheita do café e pagava parte dos produtos industrializados comprados pela loja.

Outro caso similar ocorre nas transações com a Oliveira Valle e Cia (APFBV. Livro, n. 2, p. 224), marcando a maior compra da loja, feita no valor de $16: 401 \$ 000$, que foi quitado no período de oito meses, mediante uma pequena taxa de juros. A loja, ao realizar os pagamentos, lançou um valor de 3:010\$000 da seguinte forma: “[...] dinheiro que entregamos a $M$. V. Levy por sua ordem". Assim, tal valor foi abatido da conta da Oliveira Valle e Cia.

Quando vamos à conta da $M$. V. Levy, na mesma data, existe um desconto no valor de 2:980\$200, pagos a seu representante, além de um “[...] desconto obtido na fatura, a vencer, de 16\$020" (APFBV. Livro, n. 2, p. 222). Então, com o desconto sobre o valor pago a M. V. Levy, chegamos a 2:964\$180; entretanto, foram cobrados da outra empresa o valor de 3:010 $\$ 000$, o que indica a parte da loja na transação entre as empresas, que foi de $45 \$ 820$.

A família Levy tinha entre seus membros pessoas há muito atreladas ao comércio do café, enquanto as empresas C. Costa, Silva Barbosa e Coimbra Irmão e Curvelo fizeram negócios atrelados a produtos agrícolas, em que também o café foi negociado por intermédio da loja de Joaquim da Cunha.

Em 57\% dos negócios feitos pela companhia Silva Barbosa, as práticas econômicas passavam por outras empresas e por produtos agrícolas que tiveram vez. Tais características dos negócios realizados na loja podem ser um indício da existência de fornecedores locais de produtos agrícolas, que utilizavam a loja como um local de negócios desses produtos, em especial o café, mas não só; entregavam o café à loja para ser negociado, que o utilizava como forma de abatimento da dívida gerada pela compra de produtos industrializados: nessa trama, a loja ganhava nas duas pontas. Nesse caso, Joaquim da Cunha estaria atuando como o representante local de companhias que compravam produtos agrícolas para a exportação, além de fazer a intermediação entre as companhias, assim construindo uma intrincada relação comercial, em que algumas empresas fornecedoras também eram compradoras, ou melhor, forneciam produtos industrializados e recebiam 
pagamento por meio de produtos agrícolas. Entre uma ponta e outra, estava a loja de Joaquim da Cunha: vendendo os produtos importados para seus clientes e repassando os produtos agrícolas, comprados localmente, para os importadores que, frequentemente, também faziam as vezes de exportadores de café.

Ao ter a possibilidade de reajustar o valor dos produtos à venda em sua loja, Joaquim da Cunha aumentou até $44 \%$ nos preços para os consumidores, podendo se proteger das instabilidades geradas pelo encilhamento. Ao poder descontar o valor dos produtos agrícolas das faturas que devia a seus fornecedores, novamente conseguia interferir nos valores, agora com vantagens de até $20 \%$, desse modo, protegendo-se do período de instabilidade econômica e formando um circuito de negócios que resumimos na figura 1 .

Figura 1 - Circuito de negócios realizados na loja.

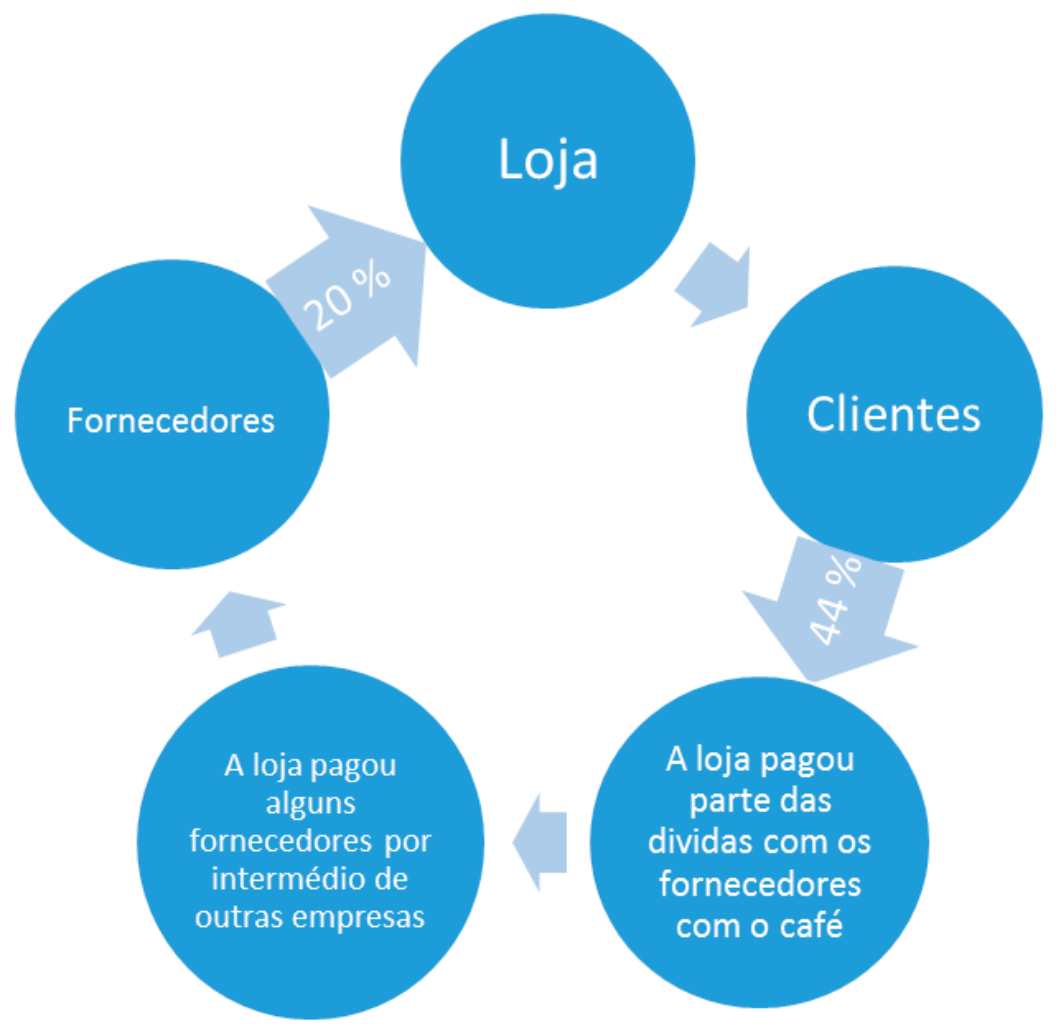

Fonte: APFBV. Livro, n. 2, 06/1891 a 04/1892.

Podemos notar, portanto, que a loja bem se defendeu da inflação da época, além de articular vários negócios, pois formou uma ampla rede. Como intermediadora desses contatos, auferindo vantagens que não estavam somente condicionados à venda de produtos de marca ou a granel, ela também era um entreposto de transações comerciais, por meio da realização de empréstimos ou do uso de notas promissórias. A loja era um espaço comercial de um membro de uma das famílias mais antigas da região, possuidora de extensas propriedades e merecedora de crédito, crédito não só utilizado por Joaquim da Cunha para o cultivo das terras, mas, também, para dilatados movimentos comerciais. Crédito e engenhosidade na realização dos negócios, sustentados por uma tradição do lugar, controlados por uma contabilidade racional em uma época de profundas mudanças na estrutura política e econômica do país, em uma cidade no centro da atividade cafeeira. 
Sendo assim, para o período estudado, a loja comprou de 44 fornecedores um total de 152:457\$000 em produtos e vendeu um total de 131:457\$000, a diferença entre os valores das compras e o valor dos pagamentos foi de 21:000\$000, conseguimos verificar que desses, ao menos 18:525\$000 foram pagos por terceiros utilizando o café como meio de pagamento, o que representou $14 \%$ dos pagamentos feitos pela loja, passaram pelo café em uma dinâmica de triangulação que envolvia mais de uma firma. Indicando a importância que esse produto tinha para o funcionamento da loja e para a realização dos pagamentos. As empresas que, em algum momento, utilizaram o café em seus negócios, movimentaram 39\% do total dos valores vendidos.

Entre as empresas com vendas acima de 1:000 réis, podemos destacar um grupo de dez companhias responsáveis pelas maiores transações; elas representam $40 \%$ das companhias que venderam acima de 1:000 réis e representaram $66 \%$ do valor de compras feitas pela loja (ver Gráfico 2). Foi nesse grupo que ocorreram as transaçóes em que os pagamentos feitos pela loja passavam por outras empresas ou pessoas. Em $14 \%$ do total de pagamentos feitos, podemos verificar a participação da loja de Joaquim da Cunha intermediando negócios entre empresas (ver Gráfico 2). Tendo em vista que o principal ativo de época era o café, não é demais apontar que o café alicerçou boa parte desses pagamentos.

As práticas comerciais que estamos apontando também ocorriam em uma esfera local, afora aquelas que eram feitas entre Ribeirão, São Paulo e Santos. O comércio regional também teve um funcionamento específico que disponibilizou produtos agrícolas e de origem animal, consumidos localmente, além dos que passavam pela estrada de ferro.

Isso é demonstrado pelos negócios feitos com a Sampaio Moreira Filho e Cia (APFBV. Livro, n. 2, p. 236, p. 241), cujos proprietários foram os donos da Fazenda Santa Cecília, com mais de 3.000 alqueires, em Cajuru-SP, a $57 \mathrm{~km}$ de Ribeirão Preto. A Sampaio Moreira vendeu 12:822\$821 à loja e recebeu, em quinze pagamentos, o valor de 8:107\$545, dos quais oito pagamentos foram feitos por meio de outras empresas que usaram a loja como intermediadora. Entre elas temos a Central Paulista, a Cana Naza e a Companbia Lacerda, a qual teve a liderança nas exportaçóes cafeeiras santistas, na metade de 1880 (SILVA, 2011). Vemos aí uma empresa da região atrelada a uma firma exportadora, a partir de um negociante local. A figura de Joaquim da Cunha, dentro de uma dinâmica do comércio local, pode ser pensada como segue:

Os comerciantes locais e regionais foram agentes fundamentais na cadeia do crédito, desempenhando funçóes importantes no que se refere às vendas a prazo. Os arranjos estabelecidos entre estes e os fazendeiros mantinham a baixa monetarização verificada entre os produtores de café, sejam eles grandes ou pequenos durante boa parte do ano agrícola. (TOSI; FALEIROS; FONTANARI, 2011, p. 405)

Um fornecedor da capital era uma loja fina de roupas masculinas que ficava na rua Direita com a XV de Novembro, em São Paulo, a Piçarra Liberal (BARBUY, 2006, p. 183), que vendia com faturas a serem pagas de sete a três meses (APFBV. Livro, n. 2, p. 325). A indumentária masculina vendida na loja compreendia: chapéus, botinas, camisas de percal, que custavam $5 \$ 000$, paletós de casimira por $15 \$ 500$, ternos de criança por $11 \$ 500$, costume de casimira que, em novembro de 1891, valia $35 \$ 000$, e, em abril de 1892 , já custava $45 \$ 000$.

As compras feitas em oito meses na loja Piçarra Liberal, como roupas de luxo, chegaram a 1:384\$400, um valor considerável. No entanto, na parte de vestuário e calçados, as botas e os 
chinelos eram os produtos mais vendidos, os quais eram fornecidos pela Fábrica de Calçados União (Livro, n. 2, p. 284), que vendia com faturas a vencer entre trinta e noventa dias, com valor agregado menor e menor prazo para pagar, diferentemente dos prazos dilatados das faturas da loja Piçarra Liberal. A fábrica de sapatos vendeu, em oito meses, 4:815\$620, um valor três vezes maior que as vendas feitas pela loja de roupas de luxo.

As empresas fornecedoras de produtos para a loja de Joaquim da Cunha podiam ser lojas finas de São Paulo, fábricas nacionais, empresas jornalísticas, produtores locais, grandes importadores que também possuíam indústrias e grandes comerciantes de Santos, como foi o caso da Ferreira de Souza $\sigma^{2}$ Cia, que vendeu 1:447\$000 em junho de 1891 (APFBV. Livro, n. 2, p. 233).

Abrangendo todos os ramos do comércio de quinquilharia, essa firma é uma das que mais negócio na cidade. A firma Ferreira de Souza é também uma das mais antigas, tendo sido estabelecida em 1875 pelo sr. M. P. Ferreira de Souza. [...] O armazém fica na Travessa Mauá 12, com 50 metros de extensão nessa rua, e 60 metros de frente para a Praça Mauá. A firma faz grandes negócios no interior do Estado, por onde traz 4 viajantes; e emprega nos seus armazéns 16 caixeiros. Os srs. Ferreira de Souza \& Cia. são agentes do Banco do Minho. (LLOYD, 1913, p. 102)

Seus proprietários eram portugueses que já moravam no Brasil há décadas e tinham experiência com o comércio no Rio de Janeiro. Essa era a característica dos importadores: eram estrangeiros com contatos no exterior, necessitavam de conhecer as leis e as oscilações aduaneiras para terem garantido os lucros e, em muitos casos, estavam envolvidos na exportação do café. Os grandes comerciantes foram os responsáveis pela aceleração do consumo, com uma posição central na circulação dos produtos importados. Ao final do século XIX, os alemães atuavam de forma agressiva no mercado, e o faziam por meio da venda de produtos com preços mais baixos que passaram a ter melhor circulação, ou mesmo pela falsificação de caros produtos franceses.

Entre as empresas alemãs, estava a importadora Zerrener, Bullow E Cia., que negociava diversos artigos, dentre eles, gêneros alimentícios, em especial, caixas de cerveja. A casa também tinha um endereço em São Paulo, na rua São Bento. Como já indicamos, a loja de Joaquim da Cunha realizou compras com a Zerrener, Bullow $\sigma^{\circ}$ Cia., no valor de 12:145\$920, o quarto maior valor de compras obtido.

No relatório da Associação Comercial de Santos, de 1886, a Zerrener, Bullow E̋ Cia. constava como exportadores de café, foi a segunda em volume de exportação entre 1885-1886 (LLOYD, 1913).

Ao entrar no mercado de exportação do café, disputou espaço com as casas de comissários, como a J. F. de Lacerda $G^{2}$ Cia, que mais exportou entre 1885-1886 - vimos a J. F. de Lacerda \& $\mathrm{Cia}$, anteriormente, fazendo negócio com a loja de Joaquim via Sampaio Moreira. Tais casas, em boa medida, eram dominadas por brasileiros; também eram brasileiros os ensacadores e representantes locais que formavam a tríade de manutenção desse negócio:

Comissário é o intermediário entre o produtor e o exportador, era o financiador e o conselheiro do fazendeiro, agindo como verdadeiros bancos regionais. As Casas de Comissários passam a ser abaladas no momento em que as casas exportadoras iniciam no mercado cafeeiro. $\mathrm{O}$ exportador representa as grandes firmas estrangeiras. Em 1896, com a queda nos preços do café, o exportado, representante da grande firma estrangeira, penetra nas fazendas e adquire o produto diretamente dos produtores. (CASALECCHI, 1976, p. 218) 
Com a chegada das grandes firmas estrangeiras no comércio do café, a figura do representante local das casas de comissários vai ser paulatinamente eliminada, e/ou substituída por um tipo de sócio do exportador estrangeiro.

Como foi o caso de Francisco Schmid, alemão que foi o maior produtor de café do Brasil, no início do século XX; teve 65 fazendas compradas com o financiamento de Theodor Wille \& Cia, grande empresa alemã exportadora de café (MORAES, 1988). Schmid mudou-se para Ribeirão, no final do século XIX, representou as casas estrangeiras que dominaram a exportação de café, pós 1895, e, no plano político, foi o maior oposicionista de Joaquim da Cunha.

Os representantes locais das casas de comissários eram pessoas com prestígio, envolvidas na cultura cafeeira, para poderem lançar mão de suas amizades na realização de negócios.

Como estamos analisando os negócios realizados nos anos de 1891 e 1892, período em que a atividade de comissário ainda era praticada, e as transaçóes feitas com várias empresas para as quais o café serviu como moeda de troca, acreditamos que Joaquim da Cunha fazia as vezes de comissário por meio da loja. De tal modo, como já demonstramos, a loja não servia somente como um espaço de venda de produtos, mas, também, um espaço de realização de variados negócios comerciais que permitiram a ele se defender das instabilidades geradas pelo encilhamento.

\section{A trama do crédito e o consumo}

A loja, em seu fluxo das variaçóes da renda, era um local em que o crédito estava disponibilizado tanto para companhias como para os clientes, além de espaço onde os produtos agrícolas davam a sustentação aos negócios, nos quais o papel de Joaquim da Cunha era de intermediário entre as compras e vendas de fornecedores locais, regionais e exportadores. A partir dessa compreensão, pesquisamos o rol de 175 clientes da loja que era dividido em empresas e pessoa física. Para o conjunto dos clientes, pretendemos buscar o perfil das compras feitas na loja e saber de que forma o crédito entrelaçava essas relaçóes.

Os produtos comprados na loja eram os mais variados, indo de alimentos consumidos no cotidiano a produtos de luxo. Como a cidade ainda não tinha um abastecimento de energia elétrica, produtos como velas, fósforos, querosene e lampióes estavam presentes na grande maioria das contas de consumidores registradas no livro da loja. Estes eram produtos adquiridos com frequência, mas que representavam em média somente $5 \%$ dos gastos - o querosene comprado em quantidade foi o que mais pesou nesses valores. Mas, o sal e o açúcar também apareceram com frequência nas compras feitas pelos clientes; o açúcar vendido era o redondo ou o mascavo; o seu fornecimento denota práticas comerciais regionais, enquanto o sal estava ligado a um comércio mais distante. Esses alimentos do cotidiano dão indícios de uma rede de comércio local e regional, para além da presença dos produtos importados. O açúcar, que já era produzido em Itu, desde o século XVIII, tem na produção regional do engenho central de Araraquara, fundado em 1889, junto à Estrada de Ferro Paulista, uma produção voltada para o mercado local. $\mathrm{O}$ arroz e suas variaçóes de tipos e marcas, como o arroz Carolina, o Nacional, o Stell, e do Japão - este último o mais vendido, além da farinha de mandioca e das batatas - representam outros alimentos do cotidiano presentes nas compras feitas na loja, que assumiram, em média, 12\% das compras.

Os produtos que dependiam do comércio regional eram derivados de animais, como ovos, carne seca, linguiça e queijos de minas. Alguns dos fornecedores de produtos locais também foram 
clientes da loja, em um processo de trocas: usavam as suas mercadorias para abaterem nas compras junto à loja. É o caso de José Guido, que “[...] paga a conta com a importância de um arreio de carroça $40 \$ 000$ [...]", depois vendido a José Lacerda de Abreu, que “[...] paga à loja a importância de $240 \$ 000$ pelos arreios de carroça fornecidos por José Guido [...]” - o lucro na venda de arreios foi significativo! (APFBV. Livro, n. 2, p. 212, p. 234, p. 261).

Entre os clientes da loja, encontramos empresas locais; nove delas utilizavam a loja para fazerem compras no atacado, como era o caso da Nogueira e Penteado, que fez compras em grandes quantidades de aguardente, que foi transportada de Córrego das Pedras. Pelo transporte entre as duas localidades, o carreiro recebeu 10\$000. Era em Córrego das Pedras que ficava a Casa Filial do Córrego das Pedras. Pelo nome e as características da conta dessa empresa, acreditamos que era uma loja atrelada à loja de Ribeirão Preto, pois comprou produtos no atacado, em quantidade muito maior que as outras empresas compravam. Por exemplo, " 1 fardo de brim paulista, no total de 439 metros, a $\$ 315$ o metro, somando $138 \$ 442$; outro fardo com 370 metros, a $\$ 340$ o metro, que somou $125 \$ 868$; 67 quilos de bacalhau, a $\$ 550$ o quilo, somando $36 \$ 850$ " (APFBV. Livro, n. 2, p. 240-299). Com essas vendas, a loja de Joaquim ganhou uma comissão de 5\%. De tal modo, as compras da "Casa Filial", entre junho e setembro de 1891, geraram compras no valor de 1:595\$000, com comissóes de $63 \$ 000$ à loja de Joaquim. Até o fim de novembro, os gastos sobem para 9:177\$222, sendo em sua totalidade liquidados, embora os pagamentos tenham sido feitos por João Itaú e Cia, pelo Coronel José Leite, José Quirino de Carvalho e a Alves e Leite e Cia, após o mês de setembro. A João Itaú e Cia também tinha uma conta junto à loja de Joaquim da Cunha, pois ali vemos o valor de 4:413:221, colocado como débito, por saldarem a dívida com a Casa Filial (APFBV. Livro, n. 2, p. 329). Outro que pagou as faturas da Casa Filial foi Alves e Leite Cia, que também teve valor lançado em conta junto à loja.

As companhias locais que compravam da loja de Joaquim da Cunha demonstram o mesmo trânsito de créditos que aquelas que vendiam à loja, tendo sempre o mês de setembro, mês da colheita do café, como o período de realizaçôes dos créditos, os quais, muitas vezes, se fizeram por intermédio de outras empresas. Uma empresa pagava a dívida com a outra, mas continuava a dever à loja de Joaquim da Cunha, como foi o caso da companhia João Itaú e Cia e Alves e Leite e Cia: por meio do dinheiro do livro, vemos o crédito como um instrumento a incitar o mercado local.

Já vimos a existência do crédito em um nível maior, que auxiliava a chegada de produtos importados; agora é o crédito auxiliando na distribuição de produtos locais, de tal modo podendo participar do jogo do comércio, que não ficou restrito aos grandes importadores e aos produtos industrializados.

Ser um cliente da loja com a possibilidade de ter as compras marcadas em um livro, contas que seriam pagas meses após os gastos, não era para qualquer um. No mínimo, era necessário ter algum tipo de proximidade, de contato, ou uma condição econômica que permitisse ao cliente tal benesse. Outra forma era utilizar da indicação de um amigo, como foi o caso de Delfino Oliveira de Araújo, que tinha uma anotação abaixo de seu nome: "abonado por Antonio Gomes Paixão", que também era cliente da loja (APFBV. Livro, n. 2, p. 330). Delfino fazia compras no atacado e usava sucessivos carretos para receber os produtos, assim como o seu 'padrinho', Antonio Gomes, (Livro, n. 2, p. 257, p. 329, p. 329), que fazia grandes compras e pagava pelo carreto para serem entregues, o que indica que as compras iam para outras localidades ou fazendas. 
As contas dos clientes da loja de Joaquim da Cunha, dependendo da movimentação, eram registradas em mais de uma entrada, em mais de uma folha. Essas folhas não eram registradas em sequência: um mesmo cliente poderia ter as suas contas dispersas por várias folhas, como foi o caso da conta de Antonio Gomes Paixão, que comprou, em seis meses, o valor de $839 \$ 320$, mas, dentro do período estudado, só pagou $255 \$ 390$. Sua dívida fora composta por compras e também por pagamentos que a loja fez em seu nome a outros, como foi o caso dos $40 \$ 000$ que a loja pagou a Carlos Paoli, uma duplicata descontada no valor de 68\$000; em fevereiro, são pagos a Estevão Lima 100\$000, a Miguel Vadichi são pagos 50\$000, e a Manoel Alves Souza, 500\$000. Todos esses pagamentos lançados em uma conta trazem-nos uma questão: a loja estava pagando as contas que o caixeiro viajante Antonio Gomes Paixão tinha contraído com outras pessoas?

No início de 1892, a loja lançou, nas contas de alguns clientes, os pagamentos feitos a terceiros. Seria este um indício de crise gerada pelo Encilhamento de Rui Barbosa? Os negócios que foram estimulados no início do encilhamento geraram contas que se tornaram insolúveis, em 1892? Se a moeda aumenta ou se o movimento de conjuntura acelera, tudo sobe; se há o aumento de crédito, facilita-se uma transação. Daí ser esse o momento em que o fornecedor de crédito será mais solicitado, o que nos permitiu dimensionar o circuito de crédito do qual a loja participou.

Um circuito de crédito percorria um sentido vertical, em direção a São Paulo e Santos, ligando-se ao grande capital; já num sentido horizontal, atuava como estímulo de práticas locais e regionais, na realização de negócios, que escorriam para o lado, atrelados ao médio e ao pequeno capital, todos interligados pela loja de Joaquim da Cunha.

O prestígio e os contatos de um membro da família Junqueira foram sendo transformados em crédito. Não só da venda de produtos a loja se mantinha, mas, também, da distribuição de produtos, de comissões, de trocas entre produtores, de intermediação entre os negócios das empresas, negócios todos garantidos por uma contabilidade, controlados por um livro de crédito e débito. Práticas econômicas arranjadas de forma tradicional, mas com um fim moderno: o lucro gerado pelo crédito. E o dinheiro para o crédito, de onde vinha? Algumas vezes, vinha do dinbeiro do livro, sustentado por produtos agrícolas; outras vezes, vinha dos clientes.

Na verdade, não só de empresas e negociantes a loja dependia; também havia os clientes, os consumidores que ali deixavam o seu dinheiro.

Entre os clientes da loja, muitos eram pessoas de reconhecido destaque na cidade; entre eles estavam onze doutores, dois coronéis, dois capitães, um fotógrafo e dez grandes produtores de café, que figuraram na relação dos maiores produtores de café da cidade (APFBV. Livro, n. 2, p. 178-437).

Pessoas da "arraia miúda” foram indicadas somente em três casos como clientes. Um desses clientes foi Jerônimo Carroceiro, que gastou $28 \$ 000$ e os pagou. Ele fazia serviços de carroceiro para a loja. Várias compras eram entregues, e o serviço era cobrado da conta do cliente. Outro cliente com tal perfil foi José Gomes, maquinista, comprador de aguardente.

Em 1891, o colono Luiz Meluci fez compra na loja e utilizou para pagar um vale no valor de $27 \$ 000$, referente à colheita de 54 alqueires de café, colhidos e recebidos em 22 de agosto de 1890. O vale foi emitido pela Fazenda Boa Vista, do próprio Joaquim da Cunha (APFBV. Livro Loja, n. 2, p. 289). A presença do vale chama a atenção, pois era utilizado como forma de evitar o emprego do dinheiro no pagamento dos empregados da fazenda Boa Vista, de Joaquim da Cunha; além disso, o vale estava sendo utilizado fora da fazenda, na loja da cidade, o que demonstra outra 
possibilidade no uso desse tipo de instrumento de pagamento que, nesse caso, não ficou recôndito à fazenda e ao seu Armazém, o que indica que Joaquim da Cunha podia monopolizar as trocas a partir dos vales, dentro e fora da fazenda.

A loja teve dois empregados que tiveram contas lançadas no livro, os seus ordenados eram acertados a cada cinco meses. Carlos Emerson recebeu seu pagamento em junho de 1891, no valor de 349\$000; em outubro, recebeu mais 330\$000, o que dá uma média de $68 \$ 000$ ao mês, valor duas vezes maior que aquele recebido pelo colono. Outro funcionário da loja era Álvaro Moreira, que recebeu de ordenado $420 \$ 000$ em outubro, só que de junho a outubro tinha retirado mercadorias e feito pequenas retiradas de dinheiro, num total de $722 \$ 000$; assim, retornou o seu salário no mesmo dia em que o recebeu e ainda ficou devendo.

Para as 150 pessoas que eram clientes, uma tendência pode ser observada em 52 contas, ou seja, 35\% dos consumidores, além de comprarem produtos, industrializados ou não, também conseguiam dinheiro junto à loja. Esses clientes retiravam valores, os mais variados, de tempos em tempos. Tais somas poderiam ser retiradas por eles, por familiares ou por empregados. Valores foram retirados para pagarem telegramas, mensalidade de clube, selos, contas de restaurante, tudo era debitado na conta do cliente. A loja vendia produtos, disponibilizava crédito para as empresas e adiantava dinheiro para os clientes, crédito e comércio estimulando a engrenagem capitalista.

Entre as pessoas que eram clientes, temos quarenta com contas que tinham as somas totais dos débitos e créditos, permitindo acompanhar a movimentação para o período entre junho de 1891 e abril de 1892. O total de compras para esses clientes alcançou os 44:292\$000, com pagamentos que chegaram a 46:888 $\$ 000$. Duas contas acabaram por comprometer a amostra. Ao eliminá-las, chegamos aos valores de compras em 32:448\$000 e de pagamentos em 24:888\$000. Como os clientes demoravam até seis meses para fazerem os seus pagamentos, temos um valor de 7:560\$000, que não foi saldado dentro do nosso recorte de estudo. Assim, acompanhamos 38 clientes, podendo destacar quinze que compraram valores superiores a 1:000\$000; oito desses sacaram dinheiro, além de comprarem produtos.

José Pereira da Silva tinha as suas contas equilibradas, até dezembro de 1891, pois começou a pagar os seus gastos com o fornecimento de produtos, como enxadas e baldes de zinco. Em seis meses, devia 518\$000, e pagou; no final de fevereiro de 1892, endivida-se, pois passou a pegar sucessivamente dinheiro junto à loja, somando $500 \$ 000 \mathrm{em}$ "dinheiro que pediu” (APFBV. Livro, n. 2, p. 186, p. 244, p. 249).

Alguns membros da família Fraga Moreira tinham por hábito a retirada de dinheiro; por exemplo, Jacinto Fraga Moreira, que teve a conta dispersada em onze entradas: começa com um gasto de $88 \$ 000$, mas, quatro meses depois, já devia $485 \$ 000$. Outro membro de sua família: Aristides Gomes Moreira: devia, em junho de 1891, 1:088\$000, e pagou 750\$000. Depois disso, pegou 90\$000; em dezembro de 1891, pegou 63\$000, em oito retiradas. Entre janeiro e março de 1892, pegou mais $98 \$ 000$, em doze retiradas; depois fez mais 25 retiradas, somando $220 \$ 000$. Além disso, continuava a consumir os produtos como vinho do Porto, lata de doces, dentre outros.

Era uma família que utilizava vários serviços da loja; outro membro, Manoel Fraga, gastou $210 \$ 000$ em produtos, de agosto a setembro de 1891, e pagou pelo conserto de um relógio $10 \$ 000$. Em janeiro, pagou ao Saturnino $14 \$ 000$, e a Carlos Paoli 18\$000; em fevereiro, pagou por um despacho de $13 \$ 000$, além das várias vezes em que pediu dinheiro. Ele também aparece em conta 
de Dona Clemência B. Fraga Moreira que, em 31 de dezembro, passou a ele 1:400\$000; esse valor não foi lançado na conta de Manoel Fraga, pois deve ter sido entregue diretamente a ele.

Dona Clemência é a única da família que inicia a conta com um crédito maior que o débito: ela tinha, em julho de 1891, um valor de 1:600\$000 de crédito, para gastos de 600\$000. Todavia, em setembro, o crédito aumentou para 2:691\$000; já no mês de novembro, o crédito foi para 7:594\$000, e, em dezembro, subiu ainda mais, para 9:821\$000, e o débito foi para 2:344\$000. Em todo tempo, em sua conta, ela teve mais crédito do que débito. E mesmo com a sua conta subindo, ela continuou com crédito; apesar de consumir bastante na loja, comprava coisas como terno de casimira a $27 \$ 800$, lata de camarão a $1 \$ 500$. Ela sempre pegava ou mandava pegar dinheiro na loja, e usava a sua conta para pagar prestadores de serviços, como o carreiro, o carpinteiro, a costureira e o alfaiate, para quem pagou mais de 500\$000. A conta na loja servia de suporte para vários gastos e compras no seu cotidiano.

Por sua vez, as entradas de dinheiro na conta de Dona Clemência ocorreram em maior valor em setembro, justamente em época de colheita do café. Um desses créditos, no valor de 1:091\$000, foi pago por Oliveira Salgado e Cia, que era uma das empresas que abasteciam a loja de Joaquim da Cunha. A conta de Dona Clemência é uma das duas que viciaram a amostra de valor total das contas fechadas, indicada anteriormente, devido ao grande valor movimentado. Além dela, a conta de Joaquim José de Faria foi outra que teve mais crédito do que débito.

Joaquim José de Faria era um grande consumidor: comprou desde dois relógios a $4 \$ 000$, dois costumes para criança a $19 \$ 000$, um aparelho de louça para criança a $1 \$ 700$, uma lata de petits pois a $8 \$ 000$, e até ovos, linguiça, gêneros para a sua fazenda, para seus colonos. Pegava dinheiro para pagar o feijão, para pagar a água, e ainda dinheiro para a mensalidade do clube, cujo valor era de $5 \$ 000$. A conta também foi marcada pelo pagamento a seus prestadores de serviços, como o sr. Pereira, que era farmacêutico e fez serviços no valor de $9 \$ 000$. Em janeiro, deu dinheiro ao sr. Paulino, no valor de $5 \$ 000$; também deu dinheiro a um colono, no valor de $2 \$ 000$; ainda dinheiro para casa, $100 \$ 000$, além de pagar ao Dr. Gabriel Horácio $15 \$ 000$. Para a lavadeira, $5 \$ 00$, para pagar a Piano e Cia por uma caixa de música, 30\$000; ao Antônio pela água, $2 \$ 000$, para o restaurante Espanhol e até do Reverendo recebeu 8\$600, via conta da loja.

É possível perceber que a conta da loja não funcionava somente como um instrumento de crédito para o cliente; ela servia como fornecedora de dinheiro, para pagar aos prestadores de serviços, aos fornecedores de produtos. Era um espaço de intermediação entre o cliente Joaquim José de Faria e outros, era onde ele deixava o seu dinheiro, tendo em vista que, para o período estudado, sempre teve na sua conta mais crédito do que débito. As entradas de dinheiro sempre eram feitas em grandes somas: em junho de 1891, “entregou dinheiro 2:000\$000"; em treze de julho, "entregou mais 2:470\$000”; em janeiro, “deposita 1:000\$000”. Depois ia retirando os valores aos poucos: em novembro, "pegou dinheiro, por vezes, $128 \$ 000$ ”, e assim ia pegando, por vezes, $66 \$ 000$, dinheiro [...]", $14 \$ 000$, em dezembro, pegou dinheiro para a água $4 \$ 000$, para cigarros $1 \$ 200$, para um parto $8 \$ 000$, e para muitos telegramas.

O movimento da sua conta junto à loja lembra a conta corrente junto a um banco. Nos negócios realizados por Joaquim José de Faria constam, como o débito a João Guimarães e Cia, 27\$760, e à Andrade Couto e irmão, pelo benefício de cinquenta arrobas de café, $16 \$ 000$. Aos poucos, o café vai surgindo como aporte das transações promovidas por ele. Em dezembro, passou a dever 9:235\$000, mas tinha um crédito de 12:439\$000. A conta dele foi a que somou mais depósitos 
e gastos, ele foi o melhor cliente de Joaquim da Cunha. Movimentou tanto dinheiro quanto a Zerrener, Bullow $\Xi^{2}$ Cia., que foi uma das cinco maiores fornecedoras da loja. Só que Joaquim José de Faria era um comprador, ou seja, um cliente, que movimentou tanto quanto uma empresa fornecedora de produtos.

Ao somarmos as contas de Joaquim de Faria e de Dona Clemência, temos um total de créditos de 21:960\$000 e de débitos de 11:579\$000. Juntos, esses dois clientes disponibilizavam um crédito de 10:381\$000, que ficou sob a tutela da loja. Esse valor é o dobro do valor médio vendido por um grande fornecedor, é mais da metade do valor que a loja adiantava de dinheiro às empresas para saldarem dívidas com outras empresas.

A loja tinha feições de banco: dava crédito, disponibilizava dinheiro, quitava outras contas dos clientes e recebia pagamentos que eram depositados nas contas dos clientes. O crédito praticado pela loja estava a meio caminho de transformá-la em um banco. Joaquim da Cunha adiantava a seus clientes o seu dinheiro, e ainda o dinheiro que lhe era confiado em depósito por terceiros, "[...] uma conta compensava a outra, à vontade do cliente, há mesmo o que chamaríamos contas a descoberto [...]” (TOSI, 2011, p. 408) desde que a loja a consista a dinâmica continuava. Nesse período, o crédito não estava somente no banco, o crédito em Ribeirão Preto também estava na loja de Joaquim da Cunha. Entre o fim da escravidão e o apogeu da cafeicultura, teve vez o crédito como elemento estimulador da dinâmica econômica local. Mas esse crédito não esteve disponível para muitos, foi um crédito disponibilizado de forma seletiva, em uma situação seletiva e amparado pelo comercio do café.

\section{Considerações finais}

A loja conseguiu se proteger do período inflacionário acarretado pelo encilhamento ao subir com frequência o valor dos produtos; por outro lado, também vendia os mesmos produtos com valores diferentes, dependendo do cliente, mas foi com o café que os ganhos foram demonstrados, quando esse meio circulante aparecia, o saldo das transaçóes subia. Como no caso de firmas que entregavam o café por um valor abaixo do que a loja repassava, ou para os clientes que, em época de colheita, aumentavam o saldo positivo e, aos poucos, iam gastando aqueles valores, possibilitando um capital de giro que muitas vezes foi usado para amparar o crédito concedido a outros consumidores.

O colono foi pago com vales; os funcionários da loja recebiam em mercadorias; os clientes da loja conseguiam dinheiro por via do dinheiro do livro. A loja movimentava muitos valores, arrumava o crédito, mas, ao que parece, não disponibilizava dinheiro vivo, uma prática que unia área rural e urbana. Por trás do movimento de crédito e de consumo disponibilizado pela loja, mais tarde ou mais cedo, encontramos o café dando aporte às transações. Café que, no final, acaba sendo comercializado pela loja e agindo como um emolumento das atividades comerciais. O café que dava aporte aos negócios realizados na loja revelou o crédito como uma importante face das atividades econômicas de Joaquim da Cunha Diniz Junqueira que chegou a ser um dos cinco maiores cafeicultores em Ribeirão Preto no início do século XX.

O consumo de biscoitos, gomas e champanhe, a realização de gastos de valor significativo, esses eram feitos por pessoas enriquecidas com o café, que tinham no consumo conspícuo uma de suas realizaçôes sociais. Estas "Não estavam interessadas em lucro nem em uma forma econômica 
de administração, mas em rendimentos estáveis para gastar com luxuosos produtos importados, como vinho francês [...]" (BURKE, 2002, p. 97-98). A conversão da riqueza em status, o consumo de todas as formas de luxo injustificado, eram uma forma estratégica de se mostrar superior a outros, em uma cidade passando por constantes mudanças, entre elas a chegada de muitos imigrantes, a invasão promovida pelo outro.

Os fazendeiros, que serão os grandes cafeicultores em 1916, não se mostraram afoitos consumidores da loja. Consumiam produtos diretamente comprados no triângulo do consumo em São Paulo e acessavam o crédito junto aos bancos por meio do financiamento hipotecário. Os que mais consumiam na loja, em 1891 e 1892, não vão constar do rol dos maiores produtores de café, em 1916.

\section{Referências}

ANDRADE, Marcos Ferreira de. Elites regionais e formação do Estado brasileiro. Minas Gerais, Campanha da Princesa, 1799-1750. Rio de Janeiro: Arquivo Nacional, 2008.

BARBUY, Heloisa. A cidade-exposição: comércio e cosmopolitismo em São Paulo, 1860-1914. São Paulo: Edusp, 2006.

BURKE, Peter. História e Teoria Social. São Paulo: Editora UNESP, 2002.

CAMPOS, Candido Malta. Os rumos da cidade: urbanismo e modernização em São Paulo. São Paulo: Senac, 2002.

CASALECCHI, José Ênio. O Fazendeiro de Café como Representante de Casa Comissária: estudo de uma correspondência. Perspectivas, v. 1, p. 217-221, 1976.

FONTANARI, Rodrigo. Um banqueiro do café: a trajetória empresarial do Coronel Christiano Osório de Oliveira e as teias do crédito na economia cafeeira paulista (1890-1937). Dissertação - (Doutorado em História Econômica), FFLCH, Universidade de São Paulo, São Paulo, 2015.

FRANCO, Gustavo Henrique Barroso. Reforma Monetária e Instabilidade Durante a Transição Republicana. Rio de Janeiro: BNDES, 1987.

GODOY, Jose Henrique Artigas de. Da opulência à ganância: coronelismo e mudança social no Oeste Paulista (1889-1930). Tese (Doutorado em Ciência Política) - Universidade de São Paulo, São Paulo, v. 1, 2006.

LLOYD, Reginald. Impressões do Brasil no Século XX: sua história, seo povo, commercio, industrias e recursos. Londres: Lloyd's Greater Britain Publishing Company, 1913. Disponível em: <http://www.novomilenio.inf.br/ santos/h0300g00.htm>. Acesso em: 29 jul. 2016.

LOPES, Luciana Suarez. O café e a cidade: a evolução das atividades urbanas em Ribeirão Preto, 1890-1933. História e Cultura, Franca, v. 4, n. 2, p. 302-318, 2015.

MARCONDES, Renato Leite; HANLEY, Anne G. Bancos na transição republicana em São Paulo: o financiamento hipotecário (1888-1901). Estudos Econômicos, São Paulo, v. 40, n. 1, p. 103-131, 2010.

MARCONDES, Renato Leite. Vastos Cafezais e Grandes Dívidas: crédito hipotecário na formação da economia cafeeira em Ribeirão Preto (1876-1914). Estudos Econômicos, São Paulo, v. 48, n. 2, p. 283-310, abr./jun. 2018.

MORAES, Maria Luiza de Paiva Melo. Atuação da firma Theodor Wille \& Cia. no mercado cafeeiro do Brasil 1844-1918. Tese (Doutorado em Faculdade de Filosofia Letras e Ciências Humanas) - Universidade de São Paulo, São Paulo, 1988.

OLIVEIRA, Jorge Henrique Caldeira de. Ribeirão Preto na República Velha: economia e riqueza através das transações imobiliárias. Doutorado (Tese), UNESP, Franca, 2006.

OLIVEIRA, Lélio Luiz de; MARCONDES, Renato Leite. Outro modo de financiar o café: hipotecas no sudoeste de Minas Gerais (1890-1914). Vária Historia, Belo Horizonte, v. 34, n. 64, p. 227-260, 2018.

OLIVEIRA, Maria Luiza Ferreira. Entre a casa e o armazém: relações sociais e experiência da urbanização em São Paulo, 1850-1900. São Paulo: Alameda, 2005. 
OLIVEIRA, Milena Fernandes. O mercado do prestígio: consumo, capitalismo e modernidade na São Paulo da ‘Belle Époque’ (1890-1914). São Paulo: Alameda, 2014.

SILVA, Gustavo Pereira. Uma dinastia do capital nacional. A formação da riqueza dos Lacerda Franco e a diversificação na economia cafeeira paulista (1803-1897). Tese (Doutorado em História) - UNICAMP, Campinas, 2011.

TOSI, Pedro Geraldo; FALEIROS, Rogério; FONTANARI, Rodrigo. Modalidades e Hierarquias do Crédito na Cafeicultura Paulista (1889-1930). Revista Brasileira de Economia (Impresso), v. 65, p. 401-412, 2011.

\section{Nota}

${ }^{1}$ Agradecemos à Coordenação de Aperfeiçoamento de Pessoal de Nível Superior (CAPES) pelo financiamento da pesquisa que gerou este artigo.

Data de recebimento: 07/04/2018

Data de aprovação: 15/09/2018 